Article

\title{
Increased Expression of Toll-Like Receptor 4 in Skin of Dogs with Discoid Lupus Erythematous (DLE)
}

\author{
Alessandro Di Cerbo *D, Sara Giusti, Francesca Mariotti, Andrea Spaterna, Giacomo Rossi (D) and Gian Enrico Magi \\ School of Biosciences and Veterinary Medicine, University of Camerino, Via Circonvallazione 93/95, \\ 62024 Matelica, Italy; sara.giusti@studenti.unicam.it (S.G.); francesca.mariotti@unicam.it (F.M.); \\ andrea.spaterna@unicam.it (A.S.); giacomo.rossi@unicam.it (G.R.); gianenrico.magi@unicam.it (G.E.M.) \\ * Correspondence: alessandro.dicerbo@unicam.it; Tel.: +39-073-740-3466
}

check for updates

Citation: Di Cerbo, A.; Giusti, S.; Mariotti, F.; Spaterna, A.; Rossi, G.; Magi, G.E. Increased Expression of Toll-Like Receptor 4 in Skin of Dogs with Discoid Lupus Erythematous (DLE). Animals 2021, 11, 1044. https://doi.org/10.3390/ani11041044

Academic Editor: Simon L. Priestnall

Received: 24 February 2021

Accepted: 6 April 2021

Published: 8 April 2021

Publisher's Note: MDPI stays neutral with regard to jurisdictional claims in published maps and institutional affiliations.

Copyright: (c) 2021 by the authors. Licensee MDPI, Basel, Switzerland. This article is an open access article distributed under the terms and conditions of the Creative Commons Attribution (CC BY) license (https:/ / creativecommons.org/licenses/by/ $4.0 /)$.
Simple Summary: Discoid lupus erythematous (DLE) is a common autoimmune skin disorder of dogs. The aim of this study was to evaluate the expression of TLR4, a bacterial lipopolysaccharide sensor, in skin of dogs with DLE and in normal skin to evaluate a possible involvement of this receptor in the disease pathogenesis. Skin samples of affected dogs had a diffuse and intense expression of TLR4, both in the epidermis and in inflammatory infiltrates. The expression was higher in DLE skin compared to normal skin. The high TLR4 expression might play an important pathogenic role in the ongoing immunopathologic process.

\begin{abstract}
Discoid lupus erythematous (DLE) is a common autoimmune skin disorder of dogs where keratinocytes play a pivotal role both in the innate and adaptive immune responses. As for the innate response, pattern recognition receptors (PRR), including Toll-like receptors (TLRs), can activate macrophages and immune tissue cells allowing for transmission and transduction of signals through cytokine and chemokine release to improve host defenses. In particular, TLR4 can also recognize endogenous molecules such as heat shock proteins produced during reactions to tissue damage. The aim of this study was to evaluate the expression of TLR4, a bacterial lipopolysaccharide sensor, in the skin of dogs with DLE and in normal skin to evaluate a possible involvement of this receptor in the disease pathogenesis. Skin samples of affected dogs had a diffuse and intense expression of TLR4 in the epidermis. Also, the inflammatory infiltrates were immunolabelled. The expression was significantly higher in DLE skin compared to normal skin ( $\left.{ }^{* * * *} p<0.0001\right)$. In conclusion, dogs with DLE showed an altered expression of TLR4, which might play an important pathogenic role in the ongoing immunopathologic process, thus being considered a valuable therapeutic potential target for DLE.
\end{abstract}

Keywords: dog; DLE; TLR4; skin; Toll-like receptors

\section{Introduction}

Dermatological issues represent almost $25 \%$ of cases referred to veterinary clinics [1]. In this sense, keratinocytes play a pivotal role both in innate and adaptive immune responses [2]. As for the innate response, it is possible to observe the activation of macrophages and immune tissue cells through pattern recognition receptors (PRR), able to distinguish between pathogen-associated molecular patterns (PAMP) and damageassociated molecular patterns (DAMP) [3]. Cell PRRs are represented by Toll-like receptors (TLRs), NOD-like receptors (NRL), RIG-like receptors (RLR), cytosolic DNA sensors (CDS), scavenger receptors, and other soluble proteins such as pentraxins, collectins, ficolins, and the complement system [4]. TLRs allow transmission and transduction of signals through cytokine and chemokine release to improve host defenses [2]. Thus, TLR activation patterns play key roles in the interaction between innate and adaptive immune responses. In particular, TLR4, a receptor known to bind bacterial LPS, can also recognize endogenous 
molecules e.g., heat shock proteins, type III fibronectin, and saturated fatty acids produced during reactions to tissue damages [5].

PRR activation is, therefore, essential to trigger cutaneous defense mechanisms against invasive pathogens, but its hyperactivation might result into uncontrolled inflammatory diseases and/or cutaneous autoimmune diseases [4]. Canine autoimmune dermatopathies represent $1-2 \%$ of cutaneous pathologies, with pemphigus and lupus erythematosus (LE) being the most common, particularly in some more predisposed breeds [6]. Moreover, despite the unclear etiology of LE, it has been argued that ulcerative and localized cutaneous lesions might be worsened by sunlight [2]. According to Gilliam and Sontheimer, there are two different canine cutaneous LE subsets, LE-specific (Vesicular, espholiative, discoid, or mucocutaneous) and LE non-specific cutaneous diseases [7].

As for discoid lupus erythematosus (DLE), it is the most common form both in human and animal species, being either localized to the facial region (FDLE) [8] or generalized, extending beyond the neck (GDLE) $[9,10]$. As far as the localized form is concerned, the age of onset of the lesions is around seven years regardless of sex, with a predisposition in German Shepperd dogs and their crosses [10]. The first cutaneous lesions of FDLE consist of erythema, depigmentation, and desquamation that progress in discoid erosions, ulcerations and atrophy, and possibly pruritus [10]. Conversely, dogs with GDLE show discoidal, multifocal, or generalized plaques with pigmentation alterations, erythematosus margins, and central alopecia in the neck, back, and thoracic region. In most of these dogs, plaques evolve into scar ulcerations characterized by an atrophic or hypertrophic central scar and an altered pigmentation [9].

Histologically, DLE is characterized by a typical interfacial pro-inflammatory pattern, rich in lymphocytes, with a vacuolar degeneration and/or apoptosis of basal keratinocytes, along with a slight thickening of the basal membrane, which is also present in the course of leishmaniasis [11]. On the contrary, GDLE interfacial dermatitis develops in the lesion boundaries. The epidermis can be atrophic or slightly hyperplastic, and depigmentation pronounced at boundaries. In chronic lesions, dermal fibrosis can confine the inflammatory infiltrate to the superficial dermis. Despite limited data about pharmacological treatment of FDLE, topical application of tacrolimus $0.1 \%$ with or without doxycycline/niacinamide combined with essential fatty acids and vitamin E seems to be the best option [12].

Notwithstanding the good response of GDLE to a wide number of treatments, most dogs have a relapse after gradual dosage decrease [9]. Nevertheless, a significant improvement or a complete remission was observed after oral administration of ciclosporin $(4.8 \mathrm{mg} / \mathrm{kg} / \mathrm{d})$ along with a short course of glucocorticoids [9].

The aim of this study was to evaluate the immunohistochemical expression of toll-like receptor 4 in DLE and normal skin of dogs to shed light on a possible involvement of this receptor in the disease physio-pathogenesis.

\section{Materials and Methods}

Twenty-four post-mortem samples, 8 from planum nasale of healthy dogs and 16 from planum nasale and/or dorsal muzzle of dogs with DLE, confirmed by histopathologic diagnosis, were collected from 2012 to 2019 at the Pathology Unit of the School of Bioscience and Veterinary Medicine of the University of Camerino (Italy) and included in this study. The specimens were fixed in $10 \%$ neutral buffered formalin, subsequently processed by an automatic histoprocessor, and embedded in paraffin. Serial sections $(3 \mu \mathrm{m})$ were stained with hematoxylin and eosin (HE).

Pathological cases were referrable to different breeds with age ranging from 2 to 10 years, $62 \%$ male and 38\% female. A serological ELISA test (Leiscan, Esteve) for leishmaniasis was carried out in all of the 16 cases, which resulted negative. In addition, immunohistochemical analysis with a monoclonal antibody anti-Kinetoplast Membrane Protein-11 (KPM11) confirmed the lack of Leishmania organisms.

All the cases resulted negative also for anti-nuclear antibody (ANA) test. Clinicalanamnestic data of all dogs were collected and summarized in Table 1. 
Table 1. Schematic representation of the 16 cases of discoid lupus erythematous (DLE) collected during the study $(\mathrm{N}=$ negative $)$.

\begin{tabular}{cccccc}
\hline Case $\mathbf{N}^{\circ}$ & Sex & Age (Years) & Breed & $\begin{array}{c}\text { Leishmania } \\
\text { Elisa-Test }\end{array}$ & Ana-Test \\
\hline 1 & Female & 5 & German Shepperd & $\mathrm{N}$ & $\mathrm{N}$ \\
2 & Male & 10 & Cocker & $\mathrm{N}$ & $\mathrm{N}$ \\
3 & Male & 2 & Akita Inu & $\mathrm{N}$ & $\mathrm{N}$ \\
4 & Male & 2 & Maremma & $\mathrm{N}$ & $\mathrm{N}$ \\
5 & Male & 7 & Shepperd & $\mathrm{N}$ & $\mathrm{N}$ \\
6 & Female & 4 & Crossbred & $\mathrm{N}$ & $\mathrm{N}$ \\
7 & Male & 3 & Collie & $\mathrm{N}$ & $\mathrm{N}$ \\
8 & Female & 4 & Collie & $\mathrm{N}$ & $\mathrm{N}$ \\
9 & Female & 4 & Retriever & $\mathrm{N}$ & $\mathrm{N}$ \\
10 & Female & 2 & Crossbred & $\mathrm{N}$ & $\mathrm{N}$ \\
11 & Male & 3 & German Shepperd & $\mathrm{N}$ & $\mathrm{N}$ \\
12 & Male & 2 & Labrador & $\mathrm{N}$ & $\mathrm{N}$ \\
13 & Female & 6 & Crossbred & $\mathrm{N}$ & $\mathrm{N}$ \\
14 & Male & 5 & Pinscher & $\mathrm{N}$ & $\mathrm{N}$ \\
15 & Male & 5 & German Shepperd & $\mathrm{N}$ & \\
16 & Male & 7 & Golden Retriever & &
\end{tabular}

Typical microscopic findings of DLE, considered as diagnostic criteria for including the cases in this study, consist in: interface (lichenoid) dermatitis characterized by a band of inflammatory cells, predominantly lymphocytes at the dermo-epidermal junction; hydropic degeneration and apoptosis (Civatte bodies) of the epidermal basal cells; melanin-laden macrophages (pigmentary incontinence) within superficial dermis (Figure 1).
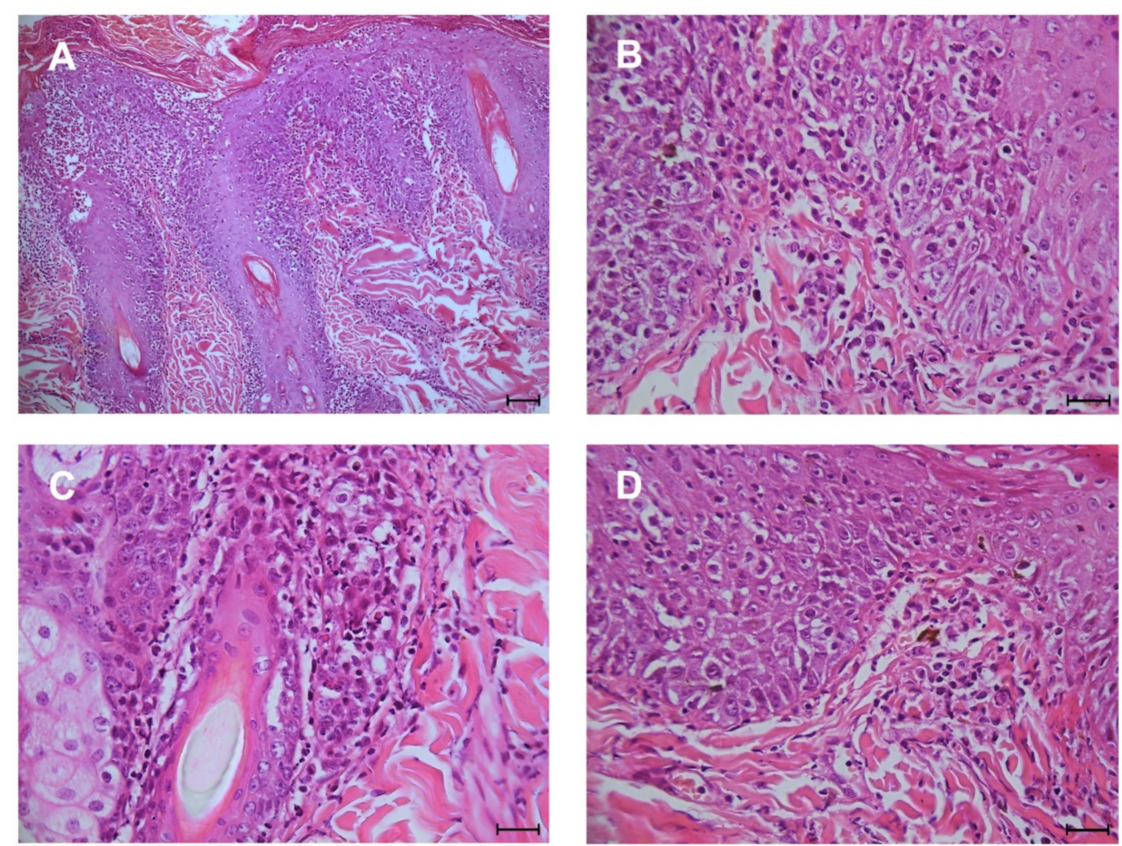

Figure 1. Histopathologic features of DLE. (A) interface dermatitis (bar $75 \mu \mathrm{m})$; $(\mathbf{B}, \mathbf{C})$ infiltrate of plasma cells and lymphocytes within dermo-epidermal junction and hydropic degeneration of keratinocytes of stratum basale (scale bar $25 \mu \mathrm{m}$ ); (D) scattered macrophages contain melanin (pigmentary incontinence) within the superficial dermis (scale bar $25 \mu \mathrm{m}$ ).

\subsection{Immunohistochemical Analysis}

Immunohistochemical analysis was carried out with a standard $\mathrm{ABC}$-peroxidase method on sections with a thickness of $3 \mu \mathrm{m}$ as described by Mariotti et al. (2019) [13]. Sec- 
tions were pre-treated with citrate buffer for antigen-retrieval, and the labelling expression of TLR4 was evaluated using a mouse monoclonal antibody anti-TLR4, clone 76B357.1, developed against a portion of 100-200 amino acids of human TLR4 (NP_612564, Novus Biologicals, Milan, Italy) diluted 1:100. As secondary antibody, a Goat anti-mouse biotinylated antibody was used along with DAB (diaminobenzidine) as chromogen. Sections were counterstained in Mayer's haematoxylin. A blocking peptide-based protocol for TLR4 was used as negative control (Supplementary Material). Labelling was evaluated by two pathologists (semi-quantitatively based on the percentage of immunopositive cells and staining intensity to obtain an expression score. An optical microscope (Leica DM 2500, Leica Microsystems Srl, Buccinasco, Italy) equipped with a camera (Leica DFC 7000T, Leica Microsystems Srl, Buccinasco, Italy) was used to acquire pictures. Each sample was firstly observed at $10 \times$ and then 5 microscopic fields at $40 \times$ were chosen for the semiquantitative evaluation. A score was then assigned to each sample according to positive cells percentage and their signal intensity.

Positive cells percentage was based on a 5-point scoring system: $0=$ none positive cell, 1 = positive cells ranging from 0 to $25 \%, 2=$ positive cells ranging from 26 to $50 \%$, 3 = positive cells ranging from 51 to $75 \%, 4=$ positive cells $>75 \%$. For each microscopic field, a count of immunopositive and negative cells was carried out and then transformed in percentage.

Regarding the intensity of the immunolabeled, it was evaluated according to a 4-point scoring system: 0 = no staining, $1=$ low-intensity staining, $2=$ moderate-intensity staining, 3 = high-intensity staining. In those samples where intensity was heterogeneous the score chosen was the predominant one in the sample itself. The overall score assigned to each sample derived by the multiplication of cell positivity and intensity signal score, with a minimum score of 0 and a maximum score of 12 . The equivocal cases were evaluated together by two authors (G.E.M. and F.M.) to establish the score.

\subsection{Statistical Analysis Mann-Whitney}

Data were analyzed using GraphPad Prism8 software (GraphPad Software, Inc., La Jolla, CA, USA). Difference in intensity score between DLE and normal skin cases was analyzed by a Mann-Whitney test. $A * p<0.05$ was considered significant.

\section{Results}

TLR4 monoclonal antibody demonstrated its suitability for normal and DLE skin fixed in neutral buffered formalin, the pre-treatment of the sections with the blocking peptide specific for the antibody used ruled out any possible false positive reactivity. The 8 samples of normal skin always showed a diffuse, positive reactivity ranging from mild (6 cases) to moderate (2 case) in the cytoplasm of epithelial cells of the epidermal layer, including those of the hair infundibulum and annexes (Figure 2). Moreover, an expression of the muscle cells of the erector pilar muscle was observed.
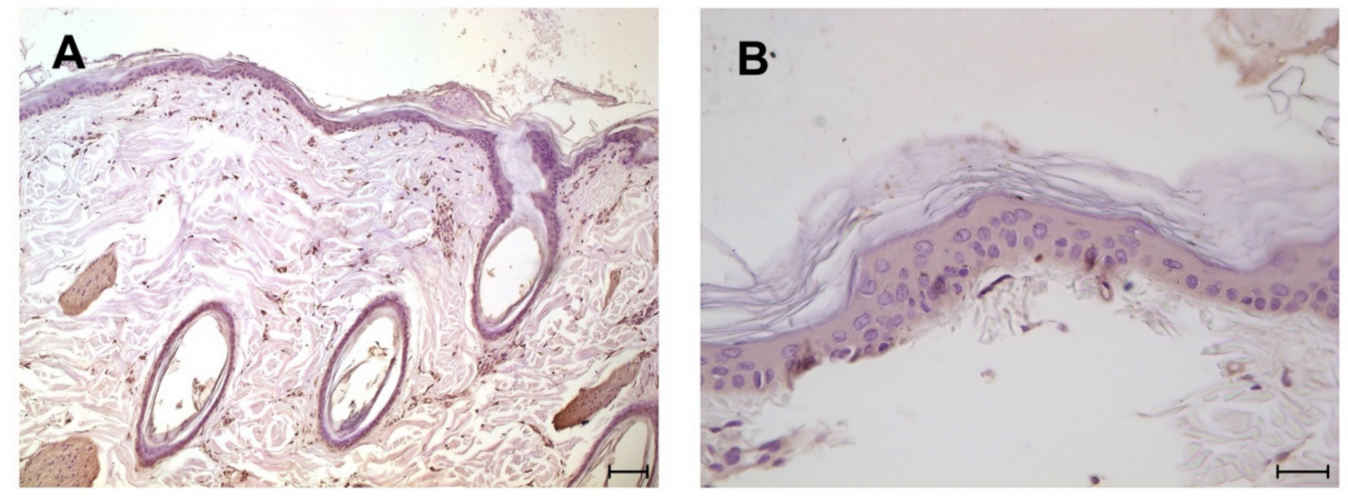

Figure 2. Immunohistochemical analysis for TLR4: normal epidermis with a low and diffuse intensity expression; (A) scale bar $75 \mu \mathrm{m}$; (B) scale bar $25 \mu \mathrm{m}$. 
As for the 16 cases of DLE, a diffuse, positive reactivity of keratinocytes of the epidermal layer was observed with a labeling intensity ranging from moderate ( 3 cases) to intense (13 cases). Epidermal epithelial cells showed a cytoplasmic immunopositivity with membrane reinforcement (Figure 3). All DLE cases showed a diffuse immunopositivity of inflammatory cells (in particular macrophages and lymphocytes).
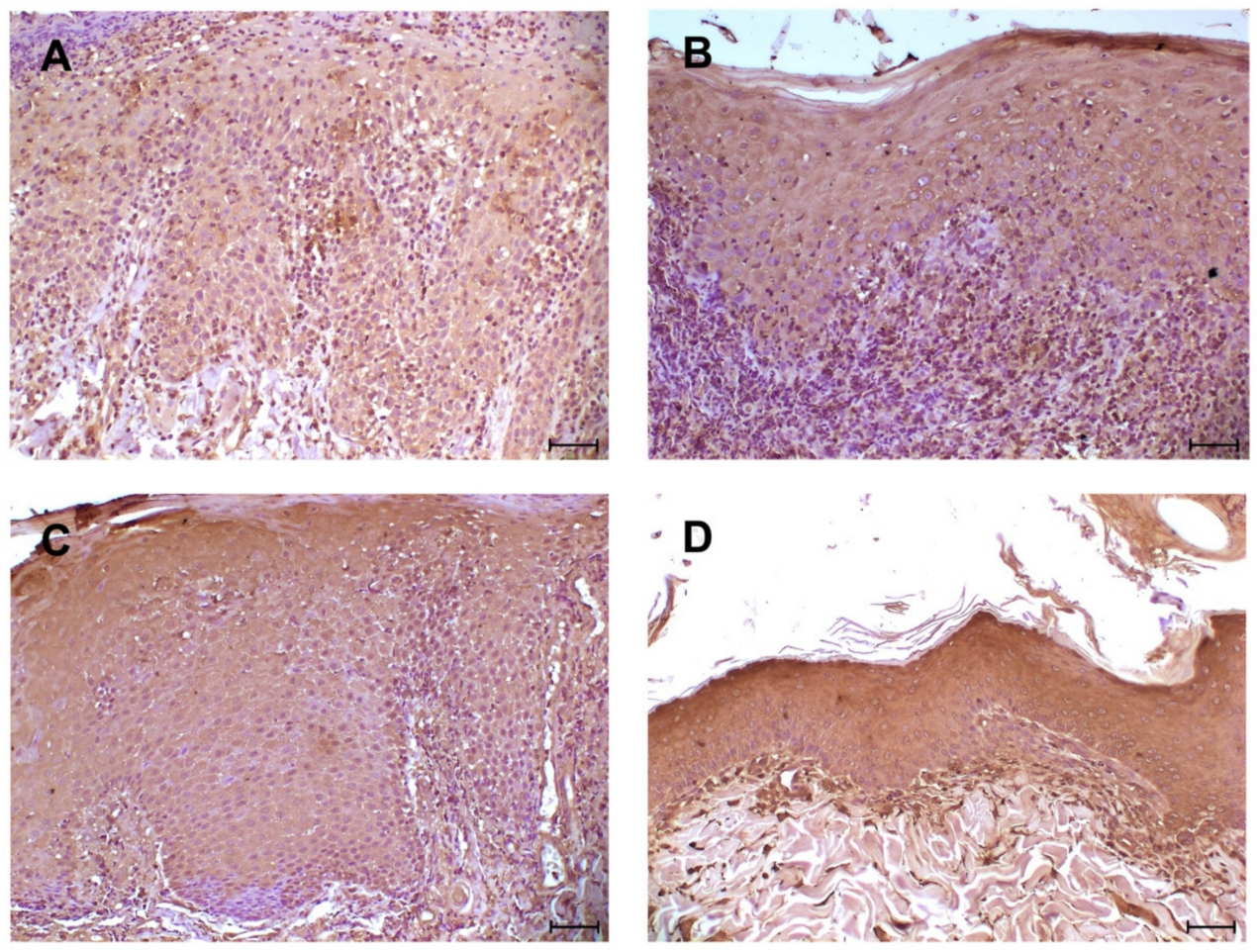

Figure 3. Immunohistochemical analysis for TLR4: four different cases of DLE with epidermis diffusely positive; (A) moderate intensity staining of the immunolabeled; (B-D) high-intensity staining of inflammatory cells. Diffuse immunolabelling of inflammatory cells at dermo-epidermal junction. (A-D) scale bar $50 \mu \mathrm{m}$.

The means of scores of DLE and normal skin cases are reported in Table 2. It is possible to observe a significant increase in DLE score with respect to that of the normal skin, $11.25 \pm 1.6$ and $4.5 \pm 1$, respectively $\left.{ }^{* * * *} p<0.0001\right)$, despite observing a positivity.

Table 2. Mean $( \pm \mathrm{SD})$ score of TRL4 expression in DLE and normal skin; ${ }^{* * *} p<0.001$.

\begin{tabular}{cccccc}
\hline & $\begin{array}{c}\text { Mean } \\
\text { Score }\end{array}$ & $\begin{array}{c}\text { Minimum } \\
\text { Score }\end{array}$ & $\begin{array}{c}\text { Maximum } \\
\text { Score }\end{array}$ & SD & $\begin{array}{c}\text { \% of Positive } \\
\text { Cases }\end{array}$ \\
\hline DLE $(\mathrm{n}=16)$ & $11.25^{* * * *}$ & 8 & 12 & 1.6 & $100(16 / 16)$ \\
Normal skin $(\mathrm{n}=8)$ & 4.5 & 4 & 6 & 1 & $100(8 / 8)$ \\
\hline
\end{tabular}

\section{Discussion}

Recent human studies demonstrated that TLR4 plays a pivotal role in autoimmune diseases, including DLE [14,15], and therefore might represent a potential target for future immunotherapeutic approaches. Beyond the binding of the lipopolysaccharide, TLR4 can also recognize both exogenous (viral glycoproteins, respiratory syncytial virus fusion proteins, and murine mammary cancer virus envelope protein) and endogenous (necrotic cells, HSP, fibronectin, fatty acids, low-density lipoproteins, and fibrinogen) ligands [14,16].

The TLR4 expression analysis carried out in normal and DLE skin sections of dogs allowed us to observe its low expression in the former and a higher expression in the latter. Intriguingly, the low TLR4 expression in normal skin seems to be in contrast with literature 
reports, which did not report any expression in such tissue [17]. The results might have a bias since the normal skin samples used in this study were obtained by post-mortem cases and, therefore, possible changes between death and fixation might have occurred, as reported in other studies $[18,19]$. However, it is undeniable that the death of the organism causes an initial peripheral hypoxia that worsens by the hour, and that the single cells, which obviously do not die with the individual, undergo a stressful event producing intrinsic signals. This could modulate the expression levels of TLR4, but also of other ligands, and therefore if the use of post-mortem samples is ethically accepted postmortem studies could present some limitations, and the results should always be interpreted considering this aspect.

In our study, six normal skin cases showed weak intensity of the immunolabeled, while only two showed a moderate intensity. We cannot rule out that this latter result might reflect a possible slight exposure to some environmental ligand/agent.

In human medicine, TLR4 expression in normal tissues is quite controversial, in particular at the epidermis level [20-22]. In this study, the localization of the immunolabeled in the keratinocytes of normal and DLE skin was mainly cytoplasmic, as reported by human studies [21-23]. In addition, an increase in TLR4 cutaneous expression was also observed in human pemphigus and systemic lupus erythematosus [15,22].

Likewise, a high TLR4 expression in the epidermis and inflammatory cells (lymphocytes and histiocytes) in biopsies of dogs with DLE are also reported. This marked expression might indicate a functional role of TLR4 during a chronic inflammatory cutaneous condition such as DLE.

However, in human medicine, the role of TLR4 in pro-inflammatory cytokine production and inflammatory cells recruitment is widely documented [24]. The high TLR4 expression in skin lesions of dogs with DLE might be linked to the presence and/or high levels of endogenous ligands, e.g., HSPs. Human studies demonstrated that intracellular HSPs synthesis increases during inflammatory and autoimmune diseases [16].

Therefore, HSPs-induced activation of TLR4 during DLE, followed by several proinflammatory cytokine production, might worsen this chronic inflammatory condition through a positive-feedback mechanism. It has been also demonstrated that hsp70 induces pro-inflammatory cytokine production through MyD88/NFkB pathway and that uses both TLR2 (Gram-positive receptor) and TLR4, by means of CD14, to transduce its proinflammatory signal [25].

In recent years, TLR4 has been directly implicated in the mechanisms and regulation of necroptosis, a newly discovered pathway of regulated necrosis induced by several stimuli, including toll-like receptors, through activation of the necrosome [26,27].

Degeneration and necrosis characteristically observed in the epidermal basal layer during DLE with associated interface inflammation could be therefore induced by such regulated cell death. In support of this hypothesis, recently in human medicine, it has been demonstrated that both necroptosis and the RIP3-dependent NLRP3 inflammasome pathways are activated in podocytes during lupus nephritis [28], likewise a type I immunity has been associated with keratinocyte necroptosis in lichen planus and lupus erythematosus, two forms of interface dermatitis [29].

\section{Conclusions}

In conclusion, we can affirm that dogs with DLE show an altered expression of TLR4, although it still remains unclear how such alteration can functionally affect the disease onset and/or progression. The high TLR4 expression might play an important pathogenic role in the ongoing immunopathogenic process. Thus, TLR4 might be considered a valuable therapeutic potential target for DLE.

Supplementary Materials: The following are available online at https:/ / www.mdpi.com/article/10 .3390/ani11041044/s1, Immunohistochemical analysis for TLR4. Case of DLE: negative control using a blocking peptide specific for the TLR4 antibody used; scale bar $50 \mu \mathrm{m}$. 
Author Contributions: Conceptualization, G.E.M.; methodology, G.E.M., G.R. and A.S.; statistical analysis, A.D.C.; investigation, A.S. and S.G.; data curation, F.M.; Writing-Original draft preparation, G.E.M. and A.D.C.; Writing-Review and Editing, G.E.M., A.D.C., F.M., A.S. and G.R.; visualization, G.E.M. and S.G.; supervision, G.E.M.; project administration, G.E.M. All authors have read and agreed to the published version of the manuscript.

Funding: This research received no external funding.

Institutional Review Board Statement: Not applicable.

Informed Consent Statement: Not applicable.

Data Availability Statement: The data presented in this study are available on request from the corresponding authors.

Conflicts of Interest: The authors declare no conflict of interest.

\section{References}

1. Schwartzman, R.M.; Orkin, M. A comparative study of canine and human dermatology. AMA Arch. Derm. 1958, 78, 630-636. [CrossRef] [PubMed]

2. McGavin, M.D.; Carlton, W.; Zachary, J.F.; Thomson, R.G. Thomson's Special Veterinary Pathology; Mosby: St. Louis, MO, USA, 2000.

3. Sun, L.; Liu, W.; Zhang, L.J. The Role of Toll-Like Receptors in Skin Host Defense, Psoriasis, and Atopic Dermatitis. J. Immunol. Res. 2019, 2019, 1824624. [CrossRef] [PubMed]

4. Abbas, A.; Lichtman, A.; Pillai, S. Cellular and Molecular Immunology; Saunders: Philadelphia, PA, USA, 2014 ; p. 544.

5. Vaure, C.; Liu, Y. A comparative review of toll-like receptor 4 expression and functionality in different animal species. Front. Immunol. 2014, 5, 316. [CrossRef] [PubMed]

6. Lee Gross, T.; Ihrke, P.J.; Walder, E.J.; Affolter, V.K. Perivascular Diseases of the Dermis. Skin Dis. Dog Cat 2005, 199-237. [CrossRef]

7. Gilliam, J.N.; Sontheimer, R.D. Distinctive cutaneous subsets in the spectrum of lupus erythematosus. J. Am. Acad. Dermatol. 1981, 4, 471-475. [CrossRef]

8. Griffin, C.E.; Stannard, A.A.; Ihrke, P.J.; Ardans, A.A.; Cello, R.M.; Bjorling, D.R. Canine discoid lupus erythematosus. Vet. Immunol. Immunopathol. 1979, 1, 79-87. [CrossRef]

9. Banovic, F.; Linder, K.E.; Uri, M.; Rossi, M.A.; Olivry, T. Clinical and microscopic features of generalized discoid lupus erythematosus in dogs (10 cases). Vet. Derm. 2016, 27, 488-e131. [CrossRef]

10. Olivry, T.; Linder, K.E.; Banovic, F. Cutaneous lupus erythematosus in dogs: A comprehensive review. BMC Vet. Res. 2018, 14, 132. [CrossRef]

11. De Lucia, M.; Mezzalira, G.; Bardagi, M.; Fondevila, D.M.; Fabbri, E.; Fondati, A. A retrospective study comparing histopathological and immunopathological features of nasal planum dermatitis in 20 dogs with discoid lupus erythematosus or leishmaniosis. Vet. Dermatol. 2017, 28, 200-e246. [CrossRef]

12. Messinger, L.; Strauss, T.; Jonas, L. A Randomized, Double-Blinded Placebo Controlled Crossover Study Evaluating 0.03\% Tacrolimus Ointment Monotherapy in the Treatment of Discoid Lupus Erythematosus in Dogs. SOJ Vet. Sci. 2017, 3, 1-6. [CrossRef]

13. Mariotti, F.; Magi, G.E.; Gavazza, A.; Vincenzetti, S.; Komissarov, A.; Shneider, A.; Venanzi, F.M. p62/SQSTM1 expression in canine mammary tumours: Evolutionary notes. Vet. Comp. Oncol. 2019, 17, 570-577. [CrossRef]

14. Richez, C.; Blanco, P.; Rifkin, I.; Moreau, J.F.; Schaeverbeke, T. Role for toll-like receptors in autoimmune disease: The example of systemic lupus erythematosus. Jt. Bone Spine 2011, 78, 124-130. [CrossRef]

15. Elloumi, N.; Fakhfakh, R.; Ayadi, L.; Sellami, K.; Abida, O.; Ben Jmaa, M.; Sellami, T.; Kammoun, K.; Masmoudi, H. The Increased Expression of Toll-Like Receptor 4 in Renal and Skin Lesions in Lupus Erythematosus. J. Histochem. Cytochem. 2017, 65, 389-398. [CrossRef]

16. Kawai, T.; Akira, S. Toll-like receptors and their crosstalk with other innate receptors in infection and immunity. Immunity 2011, 34, 637-650. [CrossRef]

17. Wassef, A.; Janardhan, K.; Pearce, J.W.; Singh, B. Toll-like receptor 4 in normal and inflamed lungs and other organs of pig, dog and cattle. Histol. Histopathol. 2004, 19, 1201-1208. [CrossRef]

18. Czapski, G.A.; Zhao, Y.; Lukiw, W.J.; Strosznajder, J.B. Acute Systemic Inflammatory Response Alters Transcription Profile of Genes Related to Immune Response and $\mathrm{Ca}(2+)$ Homeostasis in Hippocampus; Relevance to Neurodegenerative Disorders. Int. J. Mol. Sci. 2020, 21, 7838. [CrossRef]

19. Blair, J.A.; Wang, C.; Hernandez, D.; Siedlak, S.L.; Rodgers, M.S.; Achar, R.K.; Fahmy, L.M.; Torres, S.L.; Petersen, R.B.; Zhu, X.; et al. Individual Case Analysis of Postmortem Interval Time on Brain Tissue Preservation. PLoS ONE 2016, 11, e0151615. [CrossRef] 
20. Kollisch, G.; Kalali, B.N.; Voelcker, V.; Wallich, R.; Behrendt, H.; Ring, J.; Bauer, S.; Jakob, T.; Mempel, M.; Ollert, M. Various members of the Toll-like receptor family contribute to the innate immune response of human epidermal keratinocytes. Immunology 2005, 114, 531-541. [CrossRef]

21. Panzer, R.; Blobel, C.; Folster-Holst, R.; Proksch, E. TLR2 and TLR4 expression in atopic dermatitis, contact dermatitis and psoriasis. Exp. Dermatol. 2014, 23, 364-366. [CrossRef]

22. Abida, O.; Bouzid, D.; Krichen-Makni, S.; Kharrat, N.; Masmoudi, A.; Abdelmoula, M.; Ben Ayed, M.; Turki, H.; SellamiBoudawara, T.; Masmoudi, H. Potential role of TLR ligand in aethiopathogenesis of Tunisian endemic pemphigus foliaceus. Biochem. Physiol. 2013, 2, 1-5. [CrossRef]

23. Begon, E.; Michel, L.; Flageul, B.; Beaudoin, I.; Jean-Louis, F.; Bachelez, H.; Dubertret, L.; Musette, P. Expression, subcellular localization and cytokinic modulation of Toll-like receptors (TLRs) in normal human keratinocytes: TLR2 up-regulation in psoriatic skin. Eur. J. Dermatol. 2007, 17, 497-506. [CrossRef]

24. Hayashi, F.; Means, T.K.; Luster, A.D. Toll-like receptors stimulate human neutrophil function. Blood 2003, 102, 2660-2669. [CrossRef] [PubMed]

25. Asea, A.; Rehli, M.; Kabingu, E.; Boch, J.A.; Bare, O.; Auron, P.E.; Stevenson, M.A.; Calderwood, S.K. Novel signal transduction pathway utilized by extracellular HSP70: Role of toll-like receptor (TLR) 2 and TLR4. J. Biol. Chem. 2002, 277, 15028-15034. [CrossRef] [PubMed]

26. He, S.; Liang, Y.; Shao, F.; Wang, X. Toll-like receptors activate programmed necrosis in macrophages through a receptor-interacting kinase-3-mediated pathway. Proc. Natl. Acad. Sci. USA 2011, 108, 20054-20059. [CrossRef] [PubMed]

27. Pasparakis, M.; Vandenabeele, P. Necroptosis and its role in inflammation. Nature 2015, 517, 311-320. [CrossRef]

28. Guo, C.; Fu, R.; Zhou, M.; Wang, S.; Huang, Y.; Hu, H.; Zhao, J.; Gaskin, F.; Yang, N.; Fu, S.M. Pathogenesis of lupus nephritis: RIP3 dependent necroptosis and NLRP3 inflammasome activation. J. Autoimmun. 2019, 103, 102286. [CrossRef]

29. Lauffer, F.; Jargosch, M.; Krause, L.; Garzorz-Stark, N.; Franz, R.; Roenneberg, S.; Bohner, A.; Mueller, N.S.; Theis, F.J.; SchmidtWeber, C.B.; et al. Type I Immune Response Induces Keratinocyte Necroptosis and Is Associated with Interface Dermatitis. J. Investig. Dermatol. 2018, 138, 1785-1794. [CrossRef] 